
\title{
28 Research Square \\ An outbreak of Coxsackievirus A6 infection in adults of a collective unit, China, 2019
}

Yumeng Gao

Wuxi Center for Disease Control and Prevention

Guangyuan $\mathrm{Ma}$

Wuxi Center for Disease Control and Prevention

Yong Xiao

Wuxi Center for Disease Control and Prevention

Qun Cai

Hui Shan Center for Disease Control and Prevention

\section{Yujun Chen}

Wuxi Center for Disease Control and Prevention

\section{Ping Shi}

Wuxi Center for Disease Control and Prevention

\section{Yuan Shen}

Wuxi Center for Disease Control and Prevention

Chao Shi ( $\sim$ wxcdcshichao@126.com )

Wuxi Center for Disease Control and Prevention

\section{Research article}

Keywords: Coxsackievirus A6 infection, adults, outbreak

Posted Date: September 24th, 2019

DOI: https://doi.org/10.21203/rs.2.14876/v1

License: (c) (1) This work is licensed under a Creative Commons Attribution 4.0 International License.

Read Full License 


\section{Abstract}

Background: Outbreaks/epidemic caused by Coxsackievirus A6 have been reported continuously since 2008. However, outbreaks caused by Coxsackievirus A6 infection in adults of a collective unit have not been reported.

Methods: The nasopharyngeal swab specimens were collected to extract the total nucleic acid (DNA/RNA). The pathogen was determined using 22 respiratory pathogen nucleic acid detection kits. The VP1 gene of this pathogen was amplified and sequenced. Sequence alignment and analysis were performed using Bioedit. The gene phylogenetic tree was constructed with MEGA software.

Results: The factory emerged patients in succession from the February 14 and reached the peak on the 18th. The main symptoms were rash, ocular conjunctival hemorrhage, fever and sore throat. A total of 19 workers had symptoms in this factory up to March 31,2019 , giving an attack rate of $8.26 \%$. The laboratory results showed that Coxsackievirus $\mathrm{A} 6$ was the enterovirus type causing this outbreak. The risk of illness was 7.37 times higher taking bath in bathroom than that of not taking bath $(95 \% \mathrm{Cl} 1.67$, 32.79).

Conclusions: Epidemiologic and molecular data indicated Coxsackievirus A6 as the etiology of this outbreak of adults in a collective unit, a risk factor for the spread was taking bath in the bathroom of the factory.

\section{Background}

Human enteroviruses are RNA viruses in the genus Enterovirus of the Picornavirus family, which can cause a wide range of clinical manifestations [1]. They are classified into four species (A-D).

Coxsackievirus A6 (CVA6) belongs to species A [2]. Unlike enterovirus 71 (EV71) and Coxsackievirus A16 (CVA16), CVA6 infection can cause many atypical clinical manifestations and even lead to severe central nervous system disorders [3]. In addition, CVA6 currently has no vaccine, so the public health threat it caused cannot be ignored.

Since 2008, epidemic caused by CVA6 infection have been reported continuously [4-7]. In China, outbreaks/epidemic caused by this pathogen increased after 2013, and even replaced EV71 and CVA16 in many areas, becoming the dominant strain causing hand-foot and mouth disease (HFMD) [8,9]. However, outbreaks in adults caused by CVA6 infection in a collective unit have not been reported. In February 2019, an outbreak caused by CVA6 infection in adults occurred at a pharmaceutical factory in Wuxi, China. Therefore, this article will elaborate on epidemiological characteristics, clinical manifestations, risk factors and laboratory testing about this incident.

\section{Methods}


Suspected cases were defined as those with rash, who may be accompanied by symptoms such as fever, ocular conjunctival hemorrhage or other symptoms. Confirmed cases were suspected cases with the positive laboratory results of CVA6.

\section{Specimen collection}

The nasopharyngeal swab specimens were collected from 12 of the patients and placed in a sampling tube containing $3 \mathrm{ml}$ of virus sampling solution immediately on the spot. Then the specimens were immediately sent to the laboratory at $4{ }^{\circ} \mathrm{C}$ for respiratory tract pathogen nucleic acid detection.

\section{Extraction and detection of viral nucleic acid}

The total nucleic acid (DNA/RNA) was extracted using a Roche MagNA Pure LC2.0 fully automated nucleic acid extractor (Roche Applied Science, IN, USA) with the Roche MagNA pure LC total nude acid isolation kits. The extracts were dissolved in $100 \mu$ eluate and immediately stored in a $-70^{\circ} \mathrm{C}$ refrigerator. The pathogen was determined using 22 respiratory pathogen nucleic acid detection kits (Shanghai GeneoDX Biotech Co. Ltd., Shanghai, China).

\section{Amplification and sequencing of VP1 gene}

The VP1 gene primers were synthesized by Sangon Biotech (Shanghai) Co., Ltd.. Detection was performed using the QIAGEN One Step RT-PCR Kit (cat. nos. 210212, Germany). The $25 \mu$ reaction system consisted of 5 xbuffer $5 \mu \mathrm{l}, 10 \mathrm{mM}$ dNTP Mixture $1 \mu \mathrm{l}$, Enzyme Mix $1 \mu \mathrm{l}$, upstream primer $(20 \mathrm{mM}) 0.5 \mu \mathrm{l}$, downstream primer $(20 \mathrm{mM}) 0.5 \mu \mathrm{l}, \mathrm{H}_{2} \mathrm{O}$ treated by DEPC $13 \mu \mathrm{l}$ and RNA $4 \mu \mathrm{l}$. The PCR reaction conditions were $45^{\circ} \mathrm{C}$ for $30 \mathrm{~min}, 95^{\circ} \mathrm{C}$ for $15 \mathrm{~min}, 30 \mathrm{~s}$ at $94^{\circ} \mathrm{C}, 30 \mathrm{~s}$ at $56^{\circ} \mathrm{C}$, and $72{ }^{\circ} \mathrm{C}$ for $1 \mathrm{~min}$ (total $40 \mathrm{cycles}$ ), with a final extension at $72{ }^{\circ} \mathrm{C}$ for $10 \mathrm{~min}$. The amplified product was sent to Shanghai Majorbio BioPharm Technology Co., Ltd. for sequencing.

\section{Gene alignment and phylogenetic tree}

Sequence alignment and analysis were performed using Bioedit. The gene phylogenetic tree was constructed using Neighbor-Jointing (N-J) with MEGA version 4.0 software.

\section{Data analysis}

We performed descriptive epidemiologic analyses to generate hypotheses on risk factors for epidemic situation spread. Categorical variables are presented as numbers and percentages. Fisher's exact test was used to compare attack rates among different departments. The chi-square test was used to compare the difference between the incidence of bathing in the bathroom of the factory and not taking 
bath in the bathroom. Risk analysis was performed using odds ratio (OR). Analyses were performed with SPSS version 11.0 (SPSS, Chicago, IL, USA). All testing was two-sided, and $p<0.05$ was considered statistically significant.

\section{Results}

\section{Epidemiological characteristics and clinical features}

The outbreak occurred in a pharmaceutical factory of Wuxi, China. The factory has 238 employees in 13 departments, of which 7 departments are involved in this outbreak叉Fig. $1 \rrbracket$. The first case A is in the DC workshop of the production department. On February 14, 2019, case A consciously developed fever, but did not measure body temperature. The next day around 23:00, the patient found a lot of rashes (no itching) on her arms and torso, accompanied by sore throat. On the third morning, the patient developed symptoms of dry mouth, ocular conjunctival hemorrhage and the rashes spread over her face and body. Then she went to the hospital for treatment. The blood test showed the value of white blood cells was low $\left(2.92 * 10^{9} / \mathrm{L}\right)$. The doctor gave her antiviral treatment. The symptoms of ocular conjunctival hemorrhage disappeared on the fourth day. On the fifth day, the rashes subsided and the body was itchy. According to the patient's self-report, she and her family traveled to Suzhou, Shanghai and Zhoushan respectively from February 5 to February 7 , with one day in each place. Zhoushan is a coastal city with abundance of seafood. The patient ate a large amount of seafood at street stands during the tour in Zhoushan on February 7, including oysters, scallops, fish, shrimp and so on. The food ingested by the patient in Shanghai and Suzhou was healthy, without eating at street stands, no history of aquatic products except fish and freshwater shrimp, no raw and cold food. During the travel, the patient felt a little tired and weak. The patient did not have a history of exposure to similar cases. She returned to work on the 11th until 15th.

The factory emerged patients with rash, fever, ocular conjunctival hemorrhage as the main symptoms in succession from the February 15. It has spread to other workshops and reached its peak on the 18th. After taking the control measures such as disinfection, window opening and ventilation, home isolation on 19th, the number of cases has decreased, but still had cases. In order to better control the outbreak, the factory was temporarily closed on the 23rd for 10 days. Eventually, the outbreak ended on March 6 (Fig.2).

The highest percentage ( $26.32 \%$, respectively) for spatial distribution of cases was in the DC workshop where the first case was located and refining plant, followed by dissolution workshop, maintenance workshop, acylation workshop and office (10.53\%, respectively) (Fig.1). According to epidemiological investigations, all employees involved in the production of the products all leave work after taking bath in the factory's bathroom. Of the patients who developed the disease, $89.47 \%(17 / 19)$ used the bathroom. All patients had no history of exposure to similar cases outside the factory. All employees in the factory are dining in the same canteen and drinking the same batch of bottled water from the same brand. 
A total of 19 workers had symptoms up to March 31, 2019, giving an attack rate of $8.26 \%$. These patients with a male to female ratio of 1.11 to 1 , were between 22 and 42 years old. The main symptoms were rash (19 cases, $100.00 \%)$, ocular conjunctival hemorrhage (19 cases, $100.00 \%)$, fever (total 11 cases, $57.89 \% .4$ cases below $38.5^{\circ} \mathrm{C}, 5$ cases of $38.5-40.5^{\circ} \mathrm{C}, 2$ cases of conscious fever, accounting for $21.05 \%, 26.32 \%$ and $10.53 \%$ respectively) and sore throat ( 6 cases, $31.58 \%$ ). Except for one patient whose main symptom was ocular conjunctival hemorrhage, all other patients had systemic rashes, and some patients (7 cases, $36.84 \%$ ) showed symptoms of fatigue and limb joint pain in the course of disease (Fig.3, Table 1). After symptomatic treatment by doctors (mainly antipyretic, antiallergic, antivirals), the patients experienced symptoms for an average of 8 days. Two patients $(10.53 \%)$ felt itchy skin at the time of the eruption, and one patient presented with the debridement of the corners of the mouth. Five patients were not routinely examined for blood. Of the remaining 14 patients, except for 3 patients with low white blood cells, the rest was normal.

\section{Analytical research}

Analysis of the attack rates in different departments showed that there was no statistical difference in the attack rates among various departments $(p>0.05)$ (Table 2$)$.

We analyzed bathing in the bathroom as a risk factor for disease through the epidemiological investigations. The result showed that the risk of illness was 7.37 times higher taking bath in bathroom than that of not taking bath $(95 \% \mathrm{Cl} 1.67,32.79)$ (Table 3$)$.

\section{Laboratory results}

Six of 12 nasopharyngeal swabs were positive for enterovirus nucleic acid. Subsequently, the VP1 genes of the six samples were amplified, sequenced and identified by PCR. The sequencing results were analyzed by BLAST. It was found that Coxsackie A6 was the enterovirus type causing this outbreak.

The six samples became a cluster through comparison and analysis of the phylogenetic tree, which was the same branch as the original strain in the United States in 1949 (AY421764/USA1949). The homology was $91.5 \%$ (Fig.4).

\section{Discussion}

The epidemic caused by CVA6 gradually increased after 2008 [10-12]. Outbreaks in children/minors caused by CVA6 also occur frequently [13-15]. However, the outbreak of adults in a collective unit caused by CVA6 was reported for the first time.

This outbreak may be caused by CVA6 infection during the travel of the first case A, and then she returned to the factory to work to cause internal communication. This assumption is based on the following findings: Firstly, the first case A ate a large amount of seafood during the tour in Zhoushan on the 7th, 
including oysters, scallops, fish, shrimp and so on. Seafood was not handled cleanly or not cooked properly, which was prone to infection after use. Secondly, the first case A traveled from February 5 to 7. On February 14, she developed symptoms. The time was consistent with the incubation period of coxsackie A virus (generally 4-7 days) [16]. Thirdly, the first case A had a tight travel schedule and felt fatigue during the travel, which might easily reduce the immunity and increase the risk of infection.

The results of analytical research suggested that bathing in the bathroom of the factory was a risk factor for the spread冈OR: $7.37,95 \% \mathrm{Cl}: 1.67,32.79)$. Coxsackie virus is a kind of virus that can spread through respiratory and intestinal route. The bathroom is narrow, wet and has no windows. There is only a small door and the ventilation is poor, which is conducive to spread of the Coxsackie virus.

The main clinical manifestations were fever, skin rash, desquamation and onychomadesis [15,17]. A study analyzed patients with CVA6 infection in the United States in 2012 and found that the fever caused by it was more serious than other common enteroviruses [18]. The Chinese study in 2015 also showed that the proportion of fever in CVA6 group (78.69\%) was higher than that in other groups [19]. This is consistent with the study. The range of skin rash caused by the virus was wide and often brought desquamation and/or onychomadesis. In 2011, Japan reported that the rashes on the hands, palms, legs, buttocks and oral mucosa caused by CVA6 infection in children and some patients showed nail matrixes and onychomadesis [5]. In the same year, Spain also reported that children under the four years of age developed papulovesicular rash on the palms, soles, buttocks and mouth (not extend to the rest of the face) [20]. The outbreak caused by CVA6 in kindergarten in Beijing, children had skin rash (100.0\%), fever (84.3\%), desquamation (68.6\%), onychomadesis (43.1\%), even $3.9 \%$ of the children who lost all their fingernails [15]. Symptoms of fever, skin rash, desquamation and onychomadesis caused by CVA6 infection have also been reported in adult sporadic cases $[21,22]$. All patients in this study were adults. Except for one patient whose skin rash did not appear in the whole body, the rest of the patients were visible in the whole body (including the face), and the manifestation of skin rash was different from that previously reported. When the rash subsided, except for 2 patients who felt itchy skin and 1 patient who showed skin peeling at the corner of the mouth, there were no other symptoms. The patients did not appear nail matrixes or onychomadesis during the follow-up. These were different from the previously reported clinical symptoms induced by CVA6.

\section{Study limitation}

There is one limitation in this study. We were unable to obtain suspicious foods ingested by the first case A during her travel, making it impossible to determine the specific food that caused the infection.

\section{Conclusions}

Up to March 31, 2019, the attack rate of this outbreak was 8.26\%. Epidemiologic and molecular data indicated CVA6 as the etiology of this outbreak of adults in a collective unit, a risk factor for the spread 
was taking bath in the bathroom of the factory. This article is important to further understand the outbreaks caused by adult infection with CVA6.

\section{Declarations}

\section{Abbreviations}

CVA6: Coxsackievirus A6; EV71: Enterovirus 71; CVA16: Coxsackievirus A16; HFMD: Hand-foot and mouth disease; OR: Odds ratio; $\mathrm{Cl}$ : Confidence interval

\section{Ethics approval and consent to participate}

The study was conducted by public health agencies as part of their legally authorized mandate and approved by the Ethics Committee of Wuxi Center for Disease Control and Prevention. The images appeared in this manuscript that involve patients' privacy have been approved by the patients in writing.

\section{Consent for publication}

Written informed consent for publication of their clinical details and clinical images was obtained from the patients.

\section{Availability of data and material}

The datasets used and/or analyzed during the current study were mainly the patients' basic information, clinical features and laboratory test results. These involve the patients' privacy. If data must be presented, basic information about patient privacy can only be deleted to generate a series of records containing clinical characteristics and laboratory test results. The datasets are available from the corresponding authors with reasonable request through Email.

\section{Competing interests}

The authors declare that they have no competing interests.

\section{Funding}

This research was supported by Wuxi Project of Health and Family Planning (No. Z201718, MS201817), Wuxi Suitable Technical Project of Health and Family Planning (No. T201819), Project of Public Health Research Center at Jiangnan University (No. JUPH201817, JUPH201847), Wuxi Project of Key Medical Disciplines (No. ZDRC003), and Wuxi Project of Young Medical Talents(No. QNRC008). The funding body 
didn't play any role in the design of the study, the collection, analysis, interpretation of data, and writing the manuscript.

\section{Authors' contributions}

YG, YS and CS designed the study. YG, QC, YC and PS collected the data, and checked by CS and YX. YG organized and analyzed the data. $Y G$ and GM drafted the manuscript, and $Y S, C S$ and $Y X$ revised the manuscript. All authors read and approved the final manuscript.

\section{Acknowledgements}

The authors are thankful to the support from Hui Shan District Center for Disease Control and Prevention.

\section{References}

- Lefkowitz EJ, Dempsey DM, Hendrickson RC, Orton RJ, Siddell SG, Smith DB. Virus taxonomy: the database of the International Committee on Taxonomy of Viruses (ICTV). Nucleic acids research. 2018;46(D1):D708-D17.

- Pons-Salort M, Parker EP, Grassly NC. The epidemiology of non-polio enteroviruses: recent advances and outstanding questions. Current opinion in infectious diseases. 2015;28(5):479-87.

- Xu L, Zheng Q, Li S, He M, Wu Y, Li Y, et al. Atomic structures of Coxsackievirus A6 and its complex with a neutralizing antibody. Nature communications. 2017;8(1):505.

- Osterback R, Vuorinen T, Linna M, Susi P, Hyypia T, Waris M. Coxsackievirus A6 and hand, foot, and mouth disease, Finland. Emerg Infect Dis 2009;15(9):1485-8.

- Fujimoto T, lizuka S, Enomoto M, Abe K, Yamashita K, Hanaoka N, et al. Hand, foot, and mouth disease caused by coxsackievirus A6, Japan, 2011. Emerg Infect Dis. 2012;18(2):337-9.

- Puenpa J, Chieochansin T, Linsuwanon P, Korkong S, Thongkomplew S, Vichaiwattana P, et al. Hand, foot, and mouth disease caused by coxsackievirus A6, Thailand, 2012. Emerg Infect Dis. 2013;19(4):641-3.

- Zeng H, Lu J, Yang F, Liu L, Zheng H, Ke C, et al. The increasing epidemic of hand, foot, and mouth disease caused by coxsackievirus-A6, Guangdong, China, 2017. The Journal of infection. 2018;76(2):220-3.

- Zhao H, Lin H, Chen Y, Li B. Analysis of pathogeny spectrum caused hand- foot- mouth disease (HFMD) in Ningbo Yinzhou from 2012 to 2013. Chinese Journal of Health Laboratory Technology. 2014;24(17):2543-5.

- Li JL, Yuan J, Yang F, Wu ZQ, Hu YF, Xue Y, et al. Epidemic characteristics of hand, foot, and mouth disease in southern China, 2013: coxsackievirus A6 has emerged as the predominant causative agent. The Journal of infection. 2014;69(3):299-303. 
- Han JF, Xu S, Zhang Y, Zhu SY, Wu DL, Yang XD, et al. Hand, foot, and mouth disease outbreak caused by coxsackievirus A6, China, 2013. The Journal of infection. 2014;69(3):303-5.

- Wu Y, Yeo A, Phoon MC, Tan EL, Poh CL, Quak SH, et al. The largest outbreak of hand; foot and mouth disease in Singapore in 2008: The role of enterovirus 71 and coxsackievirus A strains. International Journal of Infectious Diseases ljid Official Publication of the International Society for Infectious Diseases. 2010;14(12):e1076.

- Wei SH, Huang YP, Liu MC, Tsou TP, Lin HC, Lin TL, et al. An outbreak of coxsackievirus A6 hand, foot, and mouth disease associated with onychomadesis in Taiwan, 2010. BMC infectious diseases. 2011;11:346.

- Ji Y, Wang Y, Cui H, Jin B, Kong Q. Epidemiological analysis of coxsackie virus A6 isolated from a cluster epidemic of hand foot and mouth disease in a kindergarten in Beijing (2016). Journal of Public Health and Preventive Medicine. 2017;28(02):64-7.

- Liu X, Chu Y, QIN D, Sun X, Wang Y. Epidemiological investigation of one hand-foot-mouth disease outbreak caused by Coxsackie virus A6 in a senior high school. International Journal of Virology. 2016a;23(3):160-3,7.

- Li J, Zhu R, Huo D, Du Y, Yan Y, Liang Z, et al. An outbreak of Coxsackievirus A6-associated hand, foot, and mouth disease in a kindergarten in Beijing in 2015. BMC pediatrics. 2018;18(1):277.

- Zhu J, You E, L X, Yi S. Investigation on the outbreak of hand, foot and mouth disease in a kindergarten. China Preventive Medicine. 2005(05):428.

- Upala P, Apidechkul T, Suttana W, Kullawong N, Tamornpark R, Inta C. Molecular epidemiology and clinical features of hand, foot and mouth disease in northern Thailand in 2016: a prospective cohort study. BMC infectious diseases. 2018; 18(1):630.

- Li Y, Yin D. Severe hand, foot and mouth disease caused by coxsackievirus group A type 6 from November 2011 to February 2012 in Alabama, Connecticut, California, and Nevada, USA. Chinese Journal of Vaccines and Immunization. 2012;18(05):478.

- Liu X, Chu Y, Ren J, Qin D, Kong Q, Wang Y. Comparison of epidemiology and clinical features of hand,food,and mouth disease caused by coxsackievirus A 6,enterovirus 71 and coxsackievirus A 16 in Beijing. Journal of Public Health and Preventive Medicine. 2016 b;27(05):8-11.

- Montes M, Artieda J, Pineiro LD, Gastesi M, Diez-Nieves I, Cilla G. Hand, foot, and mouth disease outbreak and coxsackievirus A6, northern Spain, 2011. Emerg Infect Dis. 2013;19(4).

- Ben-Chetrit E, Wiener-Well Y, Shulman LM, Cohen MJ, Elinav H, Sofer D, et al. Coxsackievirus A6related hand foot and mouth disease: skin manifestations in a cluster of adult patients. Journal of clinical virology: the official publication of the Pan American Society for Clinical Virology. 2014;59(3):201-3.

- Ramirez-Fort MK, Downing C, Doan HQ, Benoist F, Oberste MS, Khan F, et al. Coxsackievirus A6 associated hand, foot and mouth disease in adults: clinical presentation and review of the literature. Journal of clinical virology: the official publication of the Pan American Society for Clinical Virology. 2014;60(4):381-6. 


\section{Tables}

Due to technical limitations, Tables 1 - 3 are only available for download from the Supplementary Files section.

\section{Figures}

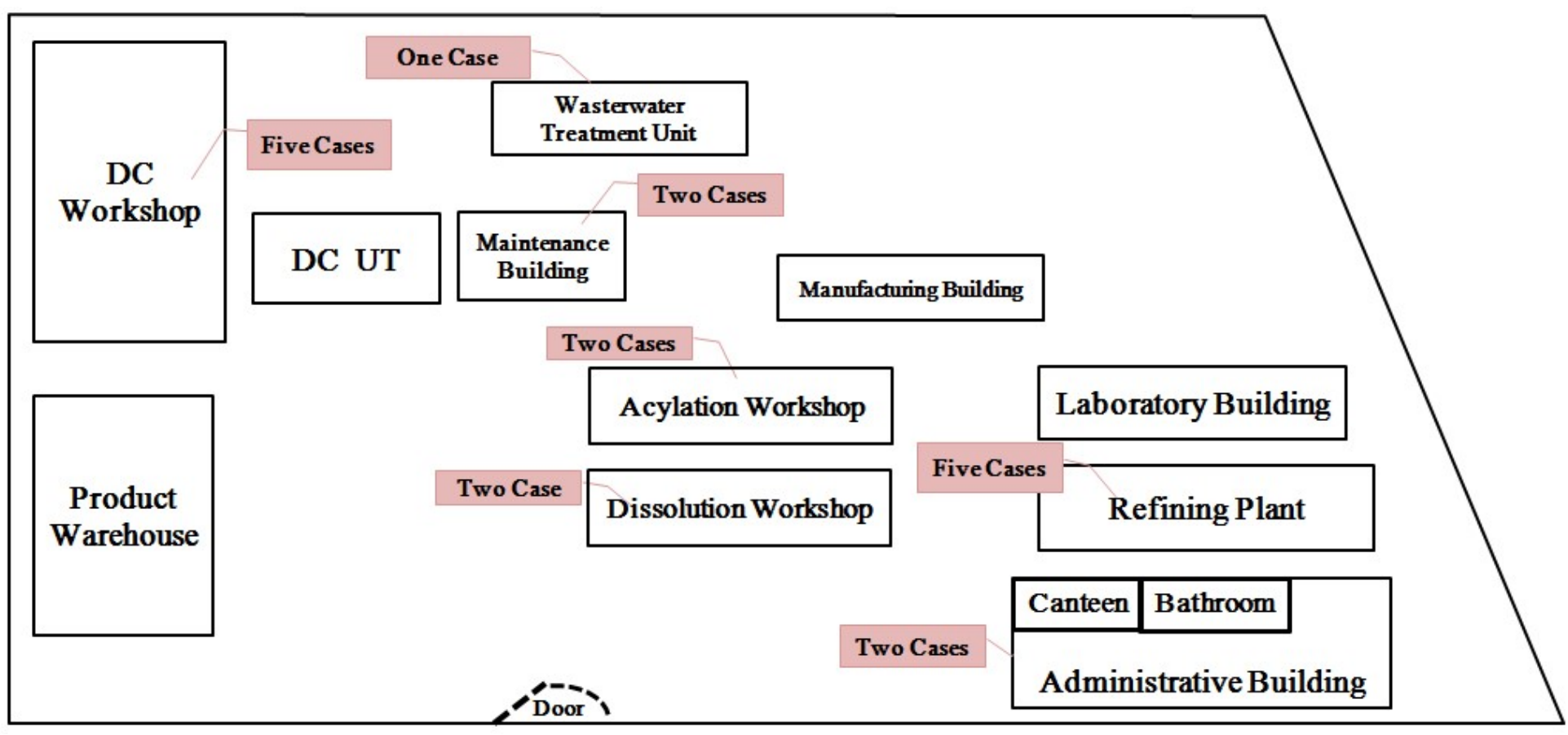

Figure 1

Workshop distribution plan of the factory

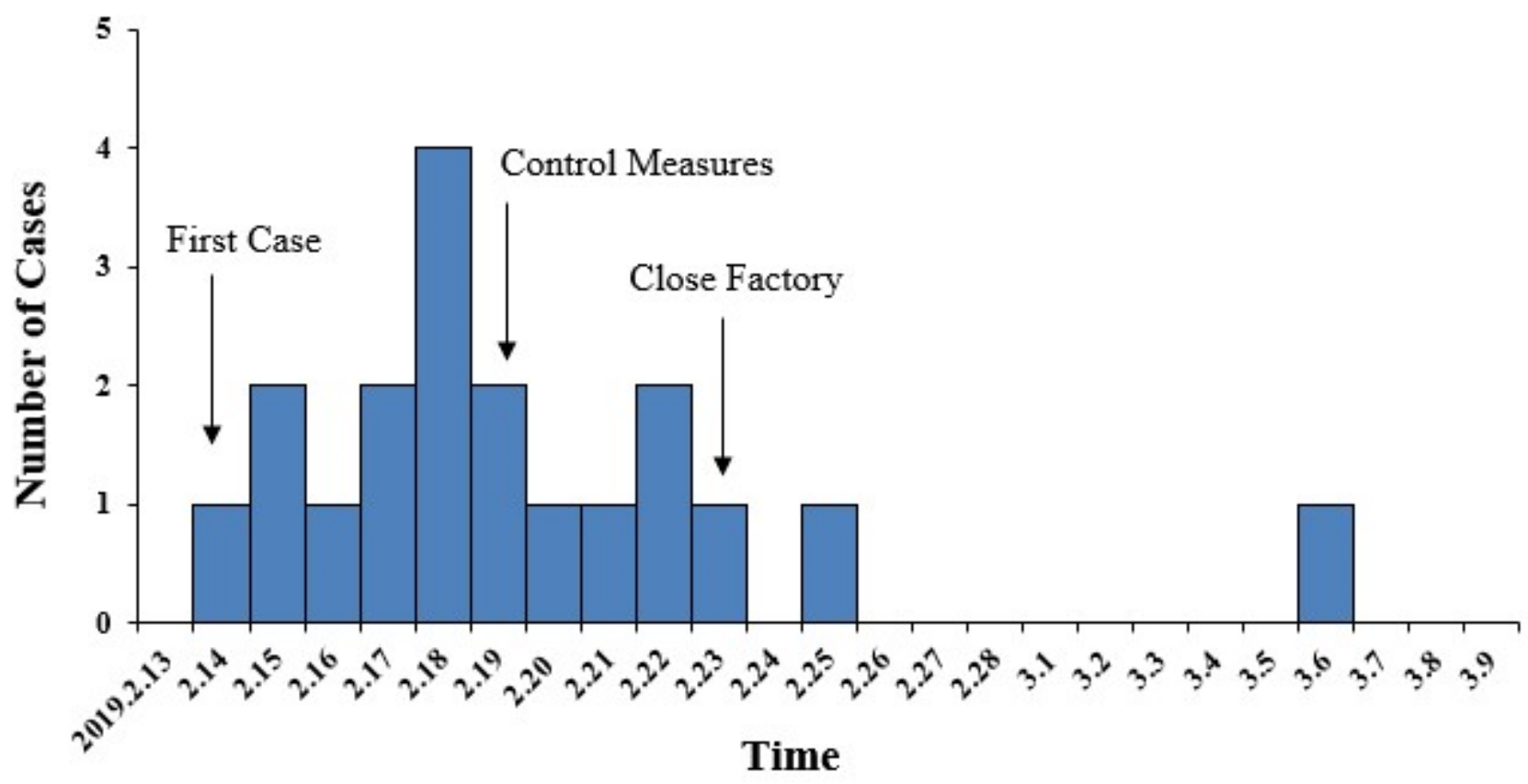


Figure 2

Distribution of cases grouped by the date of onset
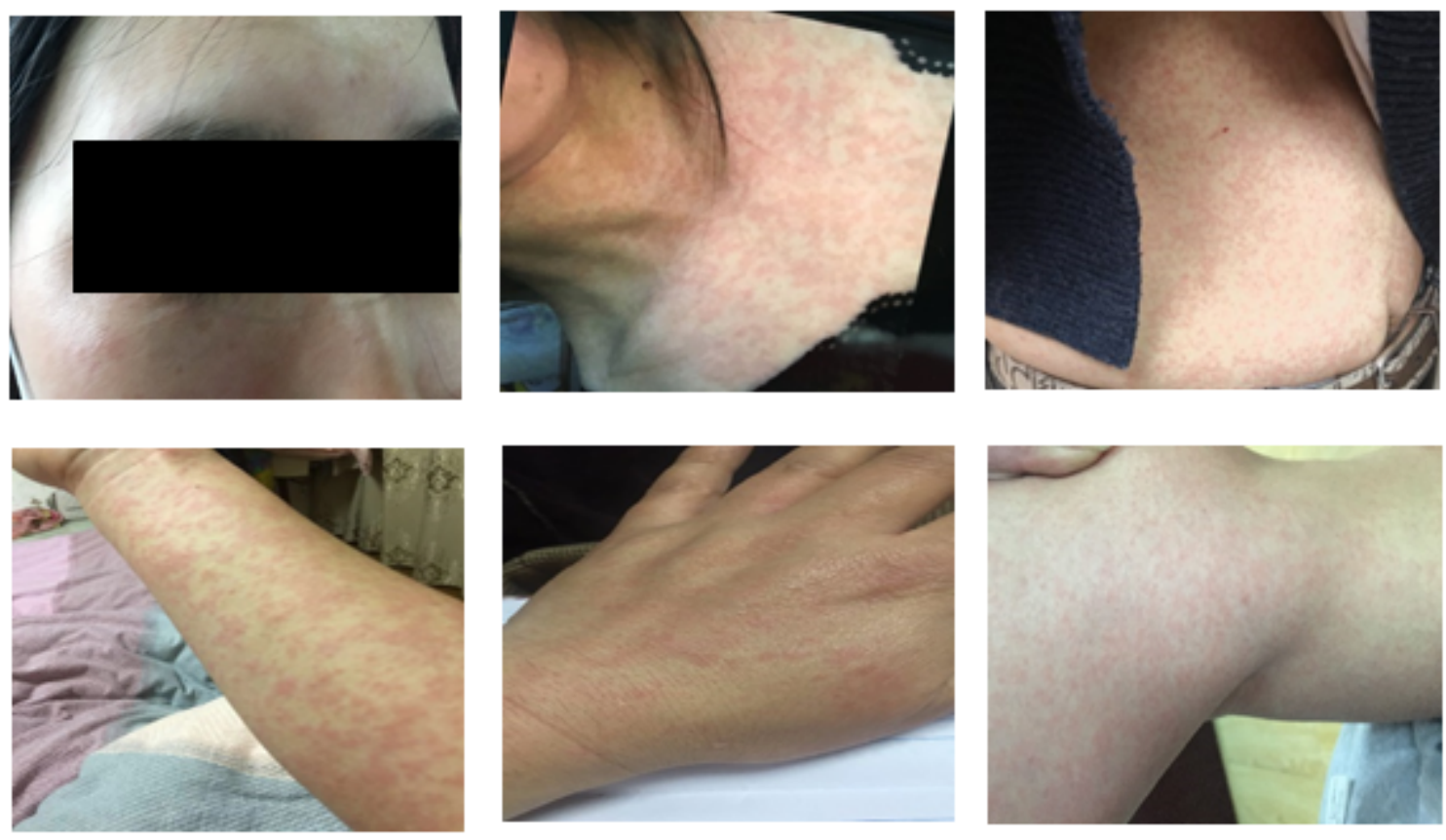

Figure 3

Typical clinical symptoms of the patients 


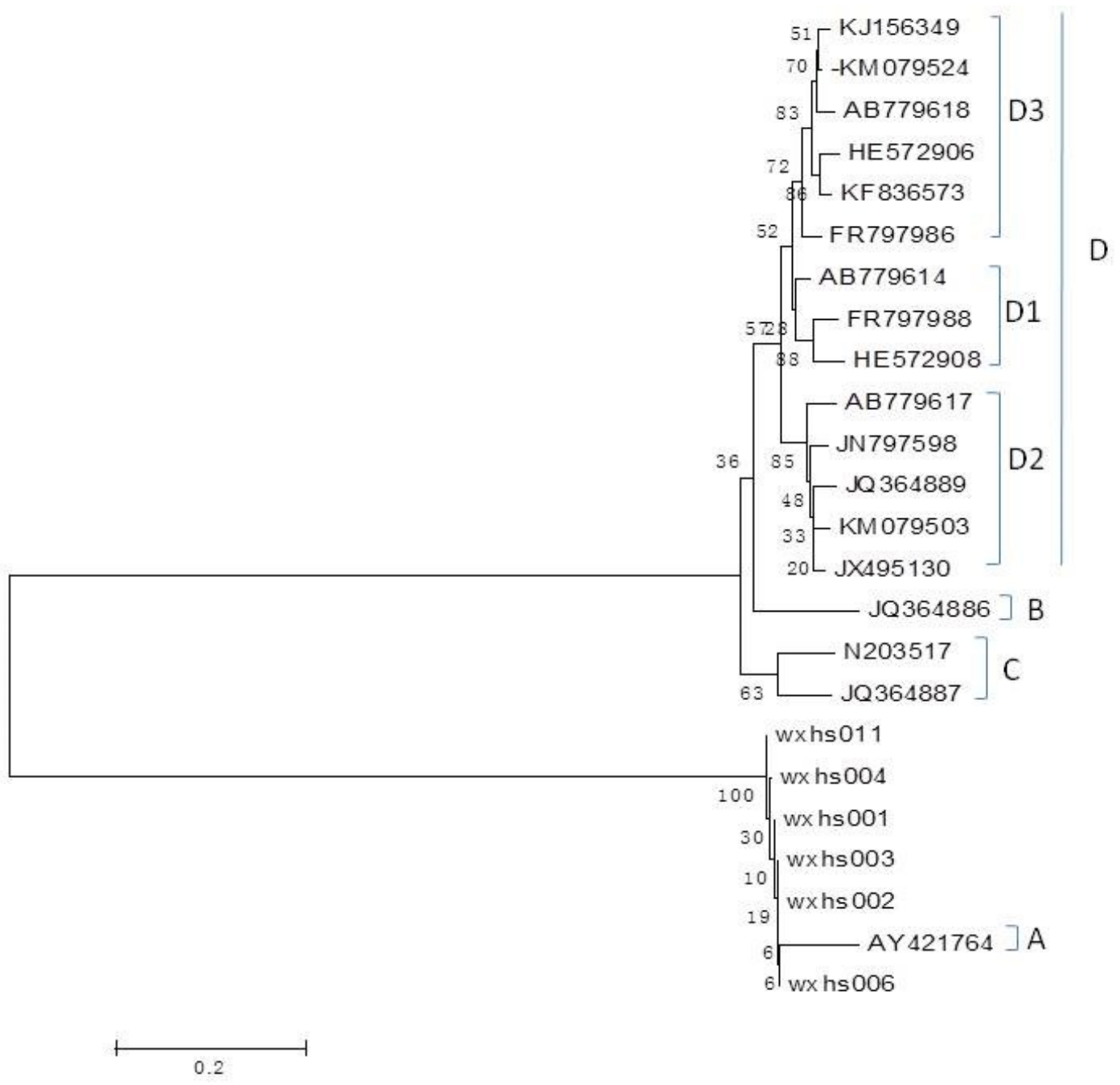

Figure 4

The phylogenetic tree of the six positive samples' VP1 genes

\section{Supplementary Files}

This is a list of supplementary files associated with this preprint. Click to download.

- Table2.pdf

- Table3.pdf

- Table1.pdf 